\title{
MANUEL PÉREZ YRUELA: LEGADO Y FUTURO DE LA SOCIOLOGÍA / UNIVERSITAT DE VALÈNCIA, 2021, 106 PÁGS. ${ }^{1}$
}

\author{
Francesc J. Hernàndez \\ Universidad de Valencia \\ ORCID: 0000-000I-5229-2998 \\ francesc.j.hernandez@uv.es \\ (c) (1) ()
}

\section{Reseña crítica}

El libro Legado y futuro de la sociología recoge el ensayo "Una mirada a la consolidación de la sociología académica y profesional en España” de Manuel Pérez Yruela, acompañado de dos escritos más, "La institucionalización de la sociología en la Universitat de València: un largo proceso" y "La mirada comprometida: tareas para una sociología de la acción”. El primero está firmado por Miguel Ángel García Calavia y el segundo por José Beltrán y Rosario Fernández-Coronado. El libro se ha publicado con motivo del cincuentenario de la enseñanza de la sociología en la Universitat de València, evento que se encadenó con la celebración del XIII Congreso Sociología promovido por la Federación Española de Sociología, que se celebró en València en el mismo año de 2019. Además de bien documentados y rigurosos, los tres textos son los suficientemente breves y claros en su esquema para exonerar al autor de este comentario de realizar, como se hace a veces en las reseñas, una síntesis. Más bien dedicaré estas líneas a conversar con los textos, id est, con sus autores y autora.

Los tres textos y de manera más patente el de Pérez Yruela se deben incluir en la disciplina de la sociología de la ciencia, más concretamente en la sociología de la sociología. No todos los saberes tiene la virtualidad reflexiva que les permita considerarse a ellos mismos como su objeto. Existe una historia de la historia (o una historiografía de la historiografía, si aceptáramos la denominación que propuso Ortega y Gasset para la ciencia histórica), una filosofía de la filosofía (al menos desde que Aristóteles escribiera el libro alfa de la Metafísica o Hegel publicara su Fenomenología del espíritu), una pedagogía de la pedagogía, una geografía de la geografía... y una sociología de la sociología; pero no, por ejemplo, una física de la física.

Recibido/Received: 08/12/202 I

Aceptado/Accepted: 2I/0I/2022 
¿Cómo hacer un abordaje sociológico de la propia sociología? La primera cuestión que se plantea es, lógicamente, la determinación del objeto a considerar: ¿es sociología solo lo que se denomina "sociología"? Mi respuesta es que no. Cuando María Carbonell, a principios del siglo $\mathrm{XX}$, organizaba visitas a las fábricas y a los barrios pobres para sus estudiantes de la sección femenina de Escuela de Magisterio de València, estaba enseñando sociología (o al menos sociología de la educación). Esta cuestión de relevancia epistemológica es la que los autores acometen con diversos conceptos, como “institucionalización” o "consolidación”. Pero cada uno de estos conceptos tiene su antónimo, que abre perspectivas al menos sugerentes: ¿qué pasa con la sociología desinstitucionalizada $\circ$ incluso antiinstitucionalizada? (pienso en algunas publicaciones anarquistas que a principios de siglo $X X$ y en medio de una dura represión proclamaban en su mancheta que eran "semanarios sociológicos" como El Corsario. Semanario sociológico que se publicó en València en 1902 o La Tramuntana. Sociologia - Interessos popululars - Arts y Lletres, que se editó en Barcelona en 1907).

Naturalmente, se podría aducir como criterio de demarcación que la "sociología" (en una etapa de "ciencia normal") es aquello que determine su "comunidad científica", invocando la autoridad de T. S. Kuhn. Es habitual la referencia a sus aportaciones conceptuales (como por ejemplo la noción de paradigma), pero, a mi modo de ver, se desconsidera su pretensión inicial: ofrecer a su estudiantado una explicación realista de la historia de su disciplina, alejada de las sistematizaciones que falsifican el esfuerzo científico. ¿Con qué frecuencia hacemos leer al estudiantado Las reglas del método sociológico de Durkheim, soslayando que el autor francés las ignoró en su gran obra sobre Las formas elementales de la vida religiosa, o el Manifiesto del partido comunista, olvidando no solo que no existía tal cosa cuando Marx escribió este panfleto, ni tan siquiera la asociación que aparece como editora en la portada (un recurso para eludir la presión policial), sino que diez años después realizó críticas definitivas a lo que había escrito allí? Por no hablar de lo habitual que resulta hacer pasar la metáfora por definición científica. (Entre paréntesis y como provocación, sugeriría una profundización en los viejos mamotretos de teología inquisitorial para que pueda apreciarse cómo la determinación de influencias malignas, o sus metamorfosis, tan frecuentes en esta literatura, no es una práctica científica, por mucho que pueda poblar cierta bibliografía sociológica).

El texto de Pérez Yruela, y también el que firma García Calavia, tienen que vérselas con una cuestión derivada de lo dicho anteriormente. Si la noción de sociología ya existía en disciplinas previas (como la metafísica de las costumbres de Kant, la filosofía del derecho de Hegel o la economía política o nacional, tal como la criticó Marx), la sociología (académica) se "consolidó" a partir del alejamiento positivista de esta matriz, y su posterior corrección comprensiva en el seno del neokantismo. Pero esta corrección, enraizada en la hermenéutica clásica, fue estilizada cuando la disciplina "emigró" a los Estados Unidos. En este punto, el positivismo del funcionalismo (con lo que tenía de orientación antimetafísica), sirvió de ariete contra la extensión del socialismo "científico". El fino análisis de la financiación de los estudios sociológicos de la Edad de Oro, realizado por Josep Picó (Los años dorados de la sociología (1945-1975)), no es menos relevante que el ejemplo de K. Lazarsfeld analizando la mentalidad de los 
comunistas que desertaban a Estados Unidos. Y esta coyuntura peculiar explica el enraizamiento paradójico de la sociología en la universidad española de la dictadura. No se trataba solo de dar rienda a una pulsión edípica, como parece sugerir Pérez Yruela (romper funcionalisticamente con la matriz filosófica), sino de cumplir con aquella función de ariete que taponara el resurgimiento de lo que había sido extirpado de las aulas. En España se dió la situación especular a la de Cuba, donde la enseñanza del marxismo cerró el paso a la de la sociología. Entre nosotros, la sociología modernizaba y no modernizaba al mismo tiempo, y la sucesión de permisos y clausuras de centros de estudios que documenta con rigor Pérez Yruela lo acredita. Ese hubiera sido el durable panorama general si no se hubiera producido la erosión de la dictadura, por un lado, y la emergencia de Mayo del 68, por el otro. (Otro paréntesis: discúlpese que "Mayo del 68" es una simplificación, tal vez excesivamente eurocéntrica, que se tendría que entender como la alusión al ciclo de luchas que incluyen la Batalla de Argel o la Matanza de Tlatelolco, entre otros acontecimientos).

En este desarrollo pendular, paradójico, a contrapelo o, si se prefiere, dialéctico de la disciplina, la sociología de la sociología, al menos desde una metodología arqueológica, debería prestar atención a los márgenes, a los fragmentos que no acaban de encajar. Un extraordinario ejemplo lo proporcionan los estudios sociolingüísticos de L. Aracil y R. Ninyoles, que comenta García Calavia. Pocas veces nuestra sociología (la procedente en este caso de la matriz del derecho) ha permitido consolidar una disciplina aplicada con semejante reconocimiento, aunque su determinación, en terminos de sociología del lenguaje o de la lengua, resulte no menos problemática y su cultivo se efectúe en la periferia peninsular. El destino de los dos intelectuales citados resulta de lo más significativo. El primero, dictando seminarios particulares sobre tanatología; el segundo, venciendo las resistencias conservadoras para realizar series demolingüísticas sobre el catalán en la Comunidad Valenciana. Los dos, al margen de la Universidad. Aunque tal vez no se haya hecho su historia, también la sociología ha tenido figuras que desarrollaron su pensamiento y gozaron de popularidad cuando dejaron las aulas superiores, como sucedió con Arthur Schopenhauer o Xavier Zubiri, en filosofía. En definitiva, la vieja tradición de B. de Spinoza.

Un buen ejemplo de sociología de la sociología lo ofrece Pérez Yruela cuando, desde la sociología de las profesiones, acomete la cuestión de las competencias requeridas para el ejercicio profesional de la sociología. Aquí se podría aplicar lo de aquella pintada que, según Galeano, se exhibía en un muro peruano: Cuando teníamos las respuestas, nos cambiaron las preguntas. Puesto que, a mi modo de ver, la cuestión principal no es qué repertorio de competencias remite la sociología profesional a la sociología académica (cuestión que Pérez Yruela plantea sociológicamente a partir de las encuestas existentes), sino qué consecuencias se derivan de que la sociología académica haya atado su destino a la institución universitaria. Que la sociología tiene una presencia marginal en el bachillerato no es más que la consecuencia del proceso histórico de determinación curricular (que hace dos siglos alumbraron el bachillerato como ciclo extra y preuniversitario, que recogía la anterior facultad menor, de artes o letras, es decir, los ancestrales trivium y cuadrivium) y son legítimos y encomiables los esfuerzos por 
dignificar su presencia en los cursos preuniversitarios. Pero esto no permite ampliar lo académico más allá de lo (pre)universitario. Que la universidad que conocemos está a las puertas de una crisis radical es una hipótesis verosímil, aunque sea una crisis de legitimidad (el nonagenario Jürgen Habermas -itodavía envidiablemente activo al escribir este texto!- mostró con precisión hace cincuenta años los deslizamientos de las crisis sistémicas en los diversos entornos en su obra -más bien un proyecto de investigaciónsobre la Crisis de legitimación del capitalismo tardío, desplazamientos que la digitalización parece haber acelerado). Por tanto, la sociología académica tendría que pensar en su acomodo también en la educación no preuniversitaria y más en general en aquello que la Carta Europea de Derechos Fundamentales define como formación profesional y permanente. "¿Qué competencias podría aportar el aprendizaje sociológico en los ciclos de formación profesional?" me parece una cuestión incluso anterior a la determinación de las competencias aportadas por la enseñanza universitaria. El ejemplo de la Formación y Orientación Laboral resulta muy significativo: otra pieza cuyo no encaje desde un análisis arqueológico resulta más que relevante para la sociología de la sociología. Por eso, a mi modo de ver, ponen el dedo en la llaga Beltrán y Fernández-Coronado cuando reclaman la atención sobre estos entornos y conceptualizan esta obertura como sociología en acción. No puedo estar más de acuerdo. Recuérdese que su uso del término compromiso es etimológico y no metafísico: ¿Cuál es la misión (-miso) que se proyecta (promiso) colectivamente (compromiso)?

Addenda. El texto de Pérez Yruela, que es un auténtico work in process que se enriquece en versiones sucesivas, podría recoger una cuestión relevante: el efecto social de ministras sociólogas y ministros sociólogos: Maravall, del Castillo, Wert y Castells. Obsérvese que todos ellos han ocupado carteras relacionadas con competencias en educación superior y también han presentado importantes leyes a la Cámara. Esto plantea dos cuestiones inquietantes. La primera: la ausencia de sociólogas o sociólogos en otras carteras (si dejamos de lado el caso del politólogo Pablo Iglesias, con un actividad ministerial difícilmente determinable en términos clásicos). La segunda: la fijación normativa. Paradójicamente, la experiencia de la II República y la de las primeras décadas de la dictadura acredita que no se precisan leyes generales u orgánicas para transformar el panorama educativo. Pero en la práctica ministerial se apunta un retroceso a la matriz jurídica. De golpe, la sociología parece recuperar la metafísica y la filosofía del derecho, a pesar de abjurar edípicamente de ella. Un buen asunto de reflexión que brindo a los autores del libro o a quien lea estas líneas.

\section{| Nota biográfica |}

Francesc J. Hernàndez es Profesor del Departamento de Sociología y Antropología social y miembro del Instituto de Creatividad e Innovaciones Educativas. Se ha dedicado a la sociología de la educación, con estancias en Alemania y Austria, con incursiones en la filosofía y la teoría social, sobre todo de autores de la Escuela de Frankfurt. Ha publicado traducciones de Marx, Kracauer, Adorno, Habermas y Honneth, entre otros, muchas en colaboración con Benno Herzog. También se ha dedicado a investigaciones sociolingüísticas relacionadas con el catalán. 